\title{
Kinetic Treatment of the Reaction of Fructose and N-Bromosuccinimide in Cationic/Anionic/Nonionic Micelles
}

\author{
Minu Singh \\ Rungta College of Engineering and Technology, Kohka-Kurud Road, Bhilai Nagar, Durg, India \\ Correspondence should be addressed to Minu Singh; minu_0511@yahoo.co.in
}

Received 2 April 2014; Revised 3 June 2014; Accepted 18 June 2014; Published 30 September 2014

Academic Editor: Eri Yoshida

Copyright (C) 2014 Minu Singh. This is an open access article distributed under the Creative Commons Attribution License, which permits unrestricted use, distribution, and reproduction in any medium, provided the original work is properly cited.

The kinetics of oxidation of fructose by $\mathrm{N}$-bromosuccinimide in acidic medium in the absence and presence of cationic, anionic, and nonionic surfactants has been measured iodometrically under pseudo-first-order condition. The oxidation kinetics of fructose by $\mathrm{N}$-bromosuccinimide shows a first-order dependence on $\mathrm{N}$-bromosuccinimide, fractional order dependence on fructose, and negative fractional order dependence on sulfuric acid. The kinetics is treated using Berezin's micellar model that was previously used for the catalysis and inhibition of the reaction. The determined stoichiometric ratio was 1:1 (fructose : N-bromosuccinimide). The variation of $\mathrm{Hg}(\mathrm{OAC})_{2}$ and succinimide (reaction product) has insignificant effect on reaction rate. Effects of surfactants, added acrylonitrile, added salts, and solvent composition variation have been studied. Activation parameters for the reaction have been evaluated from Arrhenius plot by studying the reaction at different temperatures. The rate law has been derived on the basis of obtained data. A plausible mechanism has been proposed from the results of kinetic studies, reaction stoichiometry, and product analysis.

\section{Introduction}

It is well known that aqueous charged interphases play an important role in the enhancement of the rate of chemical reactions [1-5]. Micelles act as microreactors which both speed and inhibit the rates of a wide variety of uni- and bimolecular reactions and shift the equilibrium constants of many indicators [6-15]. Aggregate effects on chemical reactivity are generally interpreted by using pseudophase models which treat micelles and water as separate reaction media, that is, separate phases or pseudophases. This approach has been successfully applied to a wide range of chemical reactions in micellar solution, including mixed micelle, and in other types of association colloids, such as microemulsions and vesicle. Surfactant aggregates affect chemical reactivity primarily by binding or excluding reactants and only secondarily by changing the free energy of activation [16-19].

Considerable attention has centred on N-bromosuccinimide (NBS) because of its versatile behaviour as mildoxidant, halogenating agent, and $\mathrm{N}$-anions, which acts both as bases and nucleophiles. NBS is well-known analytical reagent, and the mechanistic aspects of its reactions have been documented [20-25]. As a part of our mechanistic studies of oxidation of substrate by the NBS, I report the kinetics of oxidation of D-fructose by NBS in the micellar region.

Fructose, or fruit sugar, is a simple monosaccharide found in many foods. It is one of the three important dietary monosaccharides along with glucose and galactose. Honey, tree fruits, berries, melons, and some root vegetables contain significant amounts of molecular fructose, usually in combination with glucose, stored in the form of sucrose. Fructose undergoes the Maillard reaction, nonenzymatic browning, with amino acids. Fructose readily dehydrates to give hydroxymethylfurfural ("HMF"). This process may in the future be part of a low-cost, carbon-neutral system to produce replacements for petrol and diesel from plantations. Fructose is an excellent humectant and retains moisture for a long period of time even at low relative humidity $(\mathrm{RH})$. Therefore, fructose can contribute to improved quality, better 
texture, and longer shelf life to the food products in which it is used.

\section{Experimental}

2.1. Material. D-Fructose, cetyltrimethylammonium bromide (CTAB), sodium dodecyl sulfate (SDS), TritonX-100 (TX-100), succinimide (NHS), potassium iodide (KI) (all AR, s. d. fine $)$, mercuric acetate $\left(\mathrm{Hg}(\mathrm{OAc})_{2}, \mathrm{GR}\right.$, loba chemie), and sodium thiosulfate $\left(\mathrm{Na}_{2} \mathrm{~S}_{2} \mathrm{O}_{3} \cdot 2 \mathrm{H}_{2} \mathrm{O}\right.$, AR, Qualigens ExcelaR, Qualigens fine chemicals) used were of highest purity available commercially. Solutions were prepared in double distilled water. To maintain hydrogen ion concentration constant, sulfuric acid $\left(\mathrm{H}_{2} \mathrm{SO}_{4}, \mathrm{AR}\right.$, s. d. fine) was used. Distilled glacial acetic acid (AR, s. d. fine) was used as solvent. NBS (Aldrich, Germany) solution was standardized iodometrically and stored in an amber coloured bottle to avoid any photochemical deterioration [26].

2.2. Kinetic Measurements. All the kinetic measurements were carried out in an amber coloured vessel at $313 \mathrm{~K}$ and performed under pseudo-first-order condition with [Dfructose $] \gg[\mathrm{NBS}]$. The required solutions of all the reactants (except oxidant) were taken in an amber coloured reaction vessel to avoid photochemical deterioration [26]. The reaction vessel was kept in the thermostated water bath at fixed temperature and the solution was left to stand for $30 \mathrm{~min}$ to attain equilibrium. The reaction was initiated by the rapid addition of known amounts of D-fructose to a reaction mixture containing the required amount of the NBS, $\mathrm{H}_{2} \mathrm{SO}_{4}$, mercuric acetate, acetic acid, and water in glassstoppered Pyrex boiling tubes and thermostated at $313 \mathrm{~K}$. The reaction was initiated with the addition of required volume of thermally equilibrated oxidant solution. The zero time was taken when NBS solution has been added. The progress of the reaction was followed by iodometric estimation of unconsumed NBS by pipetting out aliquots at different time intervals. The kinetics was monitored for $80 \%$ completion of the reaction. The results are reproducible to within $\pm 2.5 \%$ with average linear regression coefficient.

2.3. Product Analysis and Stoichiometry. Different ratios of NBS to D-fructose were equilibrated at $313 \mathrm{~K}$ in the presence of a requisite amount of all reactants, that is, sulfuric acid, mercuric acetate, and acetic acid, under the condition of $[\mathrm{NBS}] \gg[\mathrm{D}$-fructose] for $72 \mathrm{~h}$ (when [NBS] $=$ $1.0 \times 10^{-3} \mathrm{~mol} \mathrm{dm}^{-3}$, then [fructose] $=1.0 \times 10^{-4} \mathrm{~mol} \mathrm{dm}^{-3}$ and when $[\mathrm{NBS}]=5.0 \times 10^{-4} \mathrm{~mol} \mathrm{\textrm {dm } ^ { - 3 }}$, then [fructose] $=$ $1.0 \times 10^{-4} \mathrm{~mol} \mathrm{dm}^{-3}$ ). Estimation of residual [NBS] in each set showed that $1 \mathrm{~mol}$ of fructose consumed $1 \mathrm{~mol}$ of NBS. Accordingly, the stoichiometric equation was formulated in the following equation.

\section{Product of Fructose Oxidation. Consider}

fructose + NBS $\longrightarrow$ lactone of aldonic acid + NHS
TABLE 1: Critical micelle concentration (CMC) values of surfactants in different experimental conditions.

\begin{tabular}{lcc}
\hline Solutions & $\begin{array}{c}10^{4}, \mathrm{CTAB} \\
\mathrm{mol} \mathrm{dm}^{-3}\end{array}$ & $\begin{array}{c}10^{3}, \mathrm{SDS} \\
\mathrm{mol} \mathrm{dm}^{-3}\end{array}$ \\
\hline (i) Water & 10.3 & 9.15 \\
(ii) Fructose & 9.42 & 5.23 \\
(iii) NBS & 9.90 & 9.45 \\
(iv) Acetic acid (v/v) & 9.0 & 2.26 \\
(v) $\mathrm{H}_{2} \mathrm{SO}_{4}$ & 8.20 & 1.57 \\
(vi) Fructose + NBS + acetic acid\% & 3.90 & 4.92 \\
(v/v) $+\mathrm{H}_{2} \mathrm{SO}_{4}$ & & \\
\hline
\end{tabular}

Reaction conditions: $\left[\right.$ fructose $=2.5 \times 10^{-2} \mathrm{~mol} \mathrm{dm}^{-3},[\mathrm{NBS}]=2.0 \times$ $10^{-4} \mathrm{~mol} \mathrm{dm}^{-3},\left[\mathrm{Hg}(\mathrm{OAc})_{2}\right]=5.0 \times 10^{-4} \mathrm{~mol} \mathrm{dm}^{-3},\left[\mathrm{H}_{2} \mathrm{SO}_{4}\right]=0.5 \times$ $10^{-4} \mathrm{~mol} \mathrm{dm}^{-3}$, and acetic acid $(30 \%(\mathrm{v} / \mathrm{v}))$. Literature value at $25^{\circ} \mathrm{C} \mathrm{cmc}$ of CTAB is $9.2 \times 10^{-4} \mathrm{~mol} \mathrm{dm}^{-3}$; SDS is $8.3 \times 10^{-3} \mathrm{~mol} \mathrm{dm}^{-3}$.

After the kinetic experiment was completed, a part of the oxidized reaction mixture was treated with alkaline hydroxylamine solution, and the presence of lactone in the reaction mixture was tested by $\mathrm{FeCl}_{3}-\mathrm{HCl}$ blue test $[27,28]$. To the other part of the reaction mixture, barium carbonate was added to make the solution neutral [29]. $\mathrm{FeCl}_{3}$ solution that had been coloured violet with phenol when added to this reaction mixture gave bright-yellow colouration [38], indicating the presence of aldonic acid. It is concluded that lactone, formed in the rate-determining step, is hydrolyzed to aldonic acid in neutral medium in a fast step. At higher $\mathrm{pH}$, [lactone] is reduced because of the formation of aldonic acid anion that shifts the equilibrium away from lactone.

2.4. Determination of CMC Values. The role of micellar catalysis may not be understood without its critical micelle concentration. This is the concentration where surfactant will work as micelle. Therefore, it is very interesting as well as important to know this factor very correctly and accurately. The critical micelle concentration (CMC) values of surfactants (CTAB, SDS, TX-100) in the presence and absence of substrate and oxidants (Table 1) were determined from plots of the specific conductivity (к) versus surfactant concentration using conductometric determination method and carried out with a digital conductivity meter, model 611E, at $40^{\circ} \mathrm{C}$. The values of $\mathrm{CMC}$ of surfactants are sensitive to the nature of the reactants and also depend upon reaction conditions. The break point of nearly two straight-line portions in the plot is taken as an indication of micelle formation, and this corresponds to the CMC of surfactant.

\section{Results and Discussion}

Kinetics due to molecular bromine intervention was removed by the addition of mercury (II) ions, which removed $\mathrm{Br}^{-}$ ions either as $\mathrm{HgBr}_{2}$ or as $\mathrm{HgBr}_{4}{ }^{2-}$. Here, mercuric acetate was added as a scavenger. Preliminary observations showed that the solution of CTAB became turbid in presence of $\mathrm{HClO}_{4}$. Turbidity increases with $\left[\mathrm{HClO}_{4}\right]$ at constant 
TABLE 2: Effect of substrate, oxidant, solvent, and $\mathrm{H}_{2} \mathrm{SO}_{4}$ on $k_{\text {obs }}$.

\begin{tabular}{|c|c|c|c|c|c|c|}
\hline \multirow{2}{*}{$10^{2}$, [fructose] $\mathrm{mol} \mathrm{dm}^{-3}$} & \multirow{2}{*}{$10^{4},[\mathrm{NBS}] \mathrm{Mol} \mathrm{dm}^{-3}$} & \multirow{2}{*}{$10^{4},\left[\mathrm{H}_{2} \mathrm{SO}_{4}\right] \mathrm{Mol} \mathrm{dm}^{-3}$} & \multirow{2}{*}{$\%$, acetic acid (v/v) } & \multicolumn{3}{|c|}{$10^{4}, k_{\text {obs }} \mathrm{s}^{-1}$} \\
\hline & & & & Aqueous $^{\mathrm{a}}$ & $\mathrm{CTAB}^{\mathrm{b}}$ & $\mathrm{SDS}^{\mathrm{c}}$ \\
\hline 1.0 & 2.0 & 0.5 & 30 & 0.80 & 2.0 & 0.62 \\
\hline 2.5 & & & & 1.11 & 3.50 & 0.86 \\
\hline 5.0 & & & & 1.55 & 5.40 & 1.23 \\
\hline 10.0 & & & & 2.0 & 8.0 & 1.63 \\
\hline 20.0 & & & & 2.64 & 12.10 & 2.46 \\
\hline \multirow[t]{5}{*}{2.5} & 1.0 & 0.5 & 30 & 1.13 & 3.54 & 0.88 \\
\hline & 2.0 & & & 1.11 & 3.50 & 0.86 \\
\hline & 3.0 & & & 1.11 & 3.50 & 0.85 \\
\hline & 4.0 & & & 1.10 & 3.50 & 0.84 \\
\hline & 5.0 & & & 1.10 & 3.49 & 0.84 \\
\hline \multirow[t]{5}{*}{2.5} & 2.0 & 0.50 & 30 & 1.11 & 3.50 & 0.86 \\
\hline & & 1.0 & & 0.92 & 2.60 & 0.70 \\
\hline & & 2.50 & & 0.65 & 1.75 & 0.53 \\
\hline & & 5.0 & & 0.49 & 1.32 & 0.39 \\
\hline & & 10.0 & & 0.36 & 1.0 & 0.31 \\
\hline \multirow[t]{5}{*}{2.5} & 2.0 & 0.5 & 20 & 2.09 & 5.25 & 1.0 \\
\hline & & & 25 & 1.82 & 4.60 & 0.95 \\
\hline & & & 30 & 1.11 & 3.50 & 0.86 \\
\hline & & & 40 & 0.66 & 2.30 & 0.77 \\
\hline & & & 50 & 0.48 & 1.78 & 0.65 \\
\hline
\end{tabular}

${ }^{a}$ Reaction conditions: $\left[\mathrm{Hg}(\mathrm{OAc})_{2}\right]=5.0 \times 10^{-4} \mathrm{~mol} \mathrm{dm}^{-3}$.

${ }^{\mathrm{b}}$ Reaction conditions: $\left[\mathrm{Hg}(\mathrm{OAc})_{2}\right]=5.0 \times 10^{-4} \mathrm{~mol} \mathrm{dm}^{-3}$, $[\mathrm{CTAB}]=1.2 \times 10^{-3} \mathrm{~mol} \mathrm{dm}^{-3}$.

${ }^{c}$ Reaction conditions: $\left[\mathrm{Hg}(\mathrm{OAc})_{2}\right]=5.0 \times 10^{-4} \mathrm{~mol} \mathrm{dm}^{-3}$, $[\mathrm{SDS}]=1.0 \times 10^{-2} \mathrm{~mol} \mathrm{dm}^{-3}$.

[CTAB]. Therefore, $\mathrm{H}_{2} \mathrm{SO}_{4}$ was used to maintain the acidic strength constant.

3.1. Dependence on [Fructose]. The effect of varying the concentrations of fructose on rate in aqueous and micellar media showed that the reaction order is fractional. Further, a plot of $\log k_{\mathrm{obs}}$ versus $\log$ [fructose] was linear with a slope less than unity (Figure 1). The results are summarized in Table 2.

3.2. Dependence on [NBS]. The reaction is of first order in [NBS] in the absence and presence of surfactant as indicated by the linearity of a plot of log [NBS] versus time (Figure 2). This was further confirmed by the fact that the first-order rate constant is invariant with different initial concentrations of NBS (Table 2).

3.3. Dependence on $\left[\mathrm{H}_{2} \mathrm{SO}_{4}\right]$. The rate constant decreased with increasing $\left[\mathrm{H}_{2} \mathrm{SO}_{4}\right]$. A plot of $\log k_{\text {obs }}$ versus $\log$ $\left[\mathrm{H}_{2} \mathrm{SO}_{4}\right]$ was linear with a slope that is negative (Figure 4) and less than unity indicating a negative fractional order dependence on the rate on $\left[\mathrm{H}_{2} \mathrm{SO}_{4}\right]$. The results are summarized in Table 2 .

3.4. Dependence on Solvent. The rate constant decreased with increasing acetic acid content $(20-50 \%[\mathrm{v} / \mathrm{v}])$. The results are summarized in Table 2 . A plot of $\log K_{\text {obs }}$ versus $1 / \varepsilon$ was linear with a negative slope [30] (Figure 3, (2)). Blank experiments performed showed that the oxidation of acetic acid by NBS during the period of study was negligible. Consider

$$
\log k_{\mathrm{obs}}=\log k_{0}^{\prime}-\frac{Z_{A} Z_{B} e^{2} N}{2.303\left(4 \pi \varepsilon_{0}\right) d_{A B} R T} \times \frac{1}{\varepsilon},
$$

where $k_{0}^{\prime}$ is the rate constant in a medium of infinite dielectric constant, $Z_{A}$ and $Z_{B}$ are the charges of reacting ions, $d_{A B}$ refers to the size of activated complex, $T$ is absolute temperature, and $\varepsilon$ is the dielectric constant of the medium.

3.5. Dependence on $\left[\mathrm{Hg}(\mathrm{OAc})_{2}\right]$. Mercuric acetate was added to the reaction mixture as scavenger to eliminate $\mathrm{Br}^{-}$formed in the reaction, which could have produced $\mathrm{Br}_{2}$ in the reaction. The formed $\mathrm{Br}_{2}$, thus, might cause another parallel oxidation. $\mathrm{Hg}(\mathrm{OAc})_{2}$, thus, ensures the oxidation purely through NBS.

3.6. Dependence on [Succinimide]. The reaction rate is retarded by the addition of succinimide (NHS), which is one of the products of the reaction. This points to the existence of a preequilibrium step (3). Consider

$$
\mathrm{NBS}+\mathrm{H}_{2} \mathrm{O} \stackrel{k_{1}}{\leftrightharpoons} \mathrm{HOBr}+\mathrm{NHS}
$$




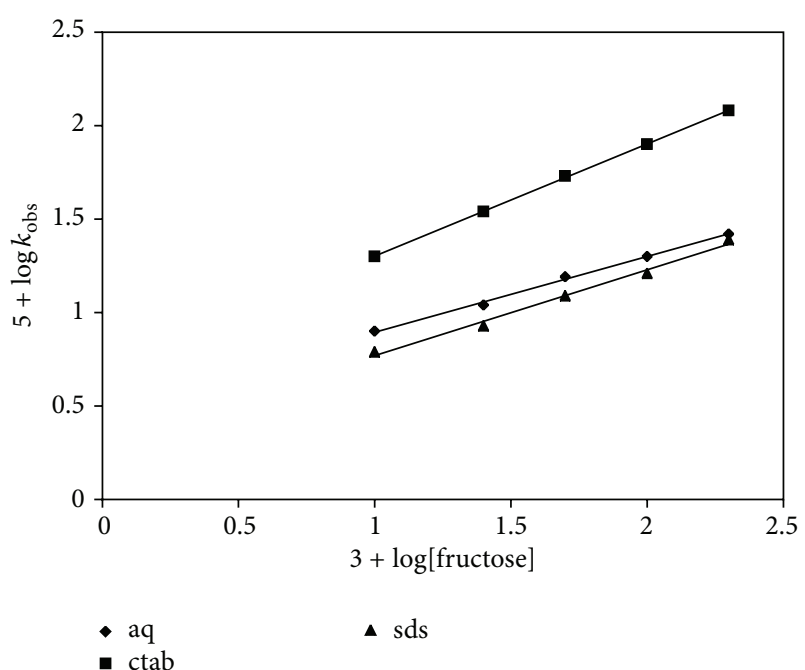

FIGURE 1: Effect of [fructose] with NBS; [NBS] $=2.0 \times 10^{-4} \mathrm{~mol} \mathrm{dm}^{-3}$, $\left[\mathrm{H}_{2} \mathrm{SO}_{4}\right]=0.5 \times 10^{-4} \mathrm{~mol} \mathrm{dm}^{-3},\left[\mathrm{Hg}(\mathrm{OAc})_{2}\right]=5.0 \times 10^{-4} \mathrm{~mol} \mathrm{dm}^{-3}$,

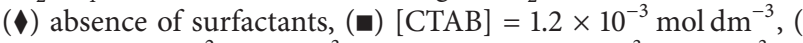
$[\mathrm{SDS}]=1.0 \times 10^{-2} \mathrm{~mol} \mathrm{dm}^{-3}$, ( TX-100 $=1.0 \times 10^{-3} \mathrm{~mol} \mathrm{dm}^{-3}, 30 \%$ (v/v) acetic acid, Temp. $40^{\circ} \mathrm{C}$.

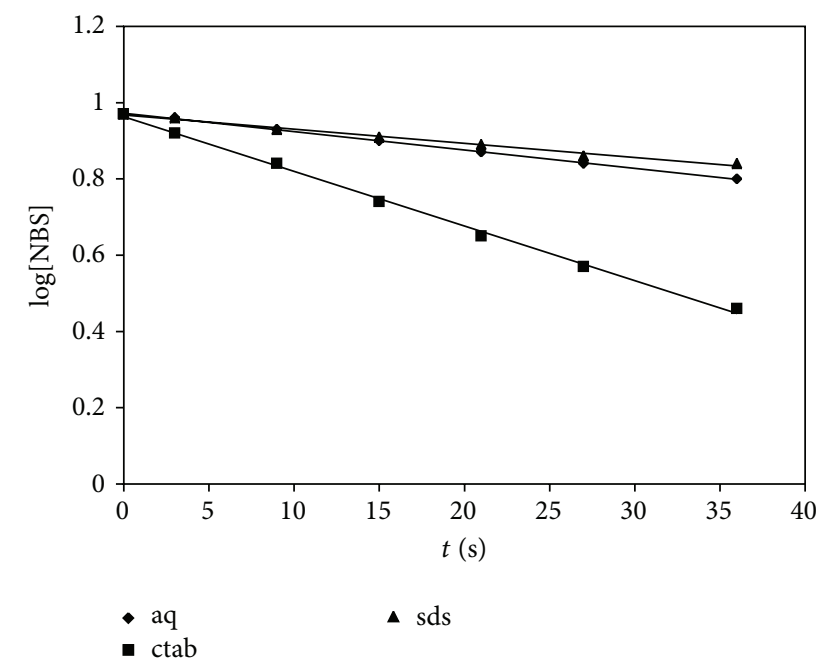

Figure 2: Effect of [NBS] on fructose; [fructose] $=2.5 \times$ $10^{-2} \mathrm{~mol} \mathrm{dm}^{-3},\left[\mathrm{H}_{2} \mathrm{SO}_{4}\right]=0.5 \times 10^{-4} \mathrm{~mol} \mathrm{dm}^{-3},\left[\mathrm{Hg}(\mathrm{OAc})_{2}\right]=5.0 \times$ $10^{-4} \mathrm{~mol} \mathrm{dm}^{-3}$, (\$) absence of surfactants, ( [CTAB] $=1.2 \times$ $10^{-3} \mathrm{~mol} \mathrm{dm}^{-3},(\mathbf{\Delta})[\mathrm{SDS}]=1.0 \times 10^{-2} \mathrm{~mol} \mathrm{dm}^{-3},(\mathbf{)}) \mathrm{TX}-100=1.0 \times$ $10^{-3} \mathrm{~mol} \mathrm{dm}^{-3}, 30 \%(\mathrm{v} / \mathrm{v})$ acetic acid, Temp. $40^{\circ} \mathrm{C}$.

The positive bromine from NBS can be transferred to the fructose through the intermediate formation of $\mathrm{HOBr}$.

3.7. Dependence on [Salt]. Added salts inhibit the micellar catalysis, which is a general phenomenon. The inhibition has been explained by assuming that the counterions compete with an ionic reactant for a site on the micelle [31] and cause shape change from spherical to rod-like micelles. The added salts $\left(\mathrm{KCl}, \mathrm{KBr}\right.$, and $\left.\mathrm{Na}_{2} \mathrm{SO}_{4}\right)$ inhibit the rate of reaction. As the concentration of these electrolytes increases,

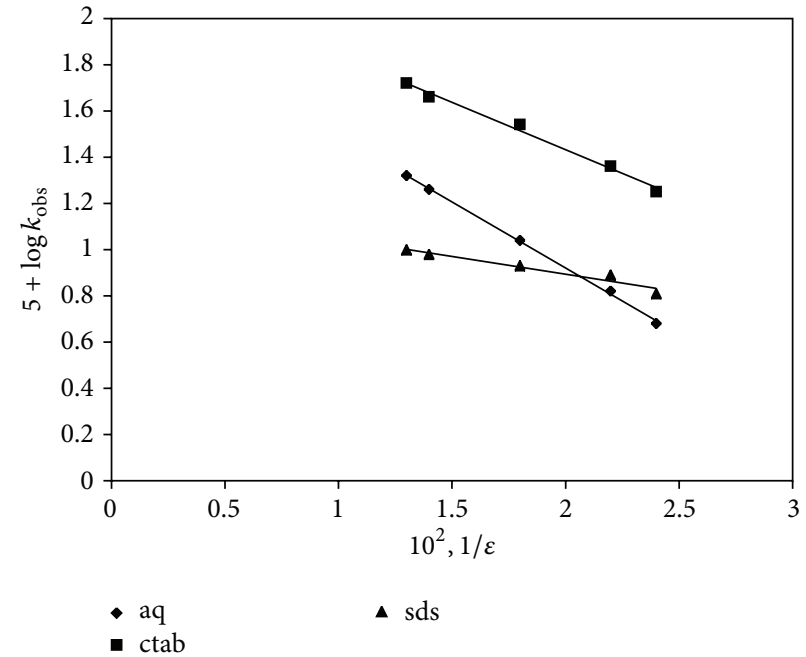

Figure 3: Effect of acetic acid\% on fructose; [fructose] $=2.5 \times$ $10^{-2} \mathrm{~mol} \mathrm{dm}^{-3},[\mathrm{NBS}]=2.0 \times 10^{-4} \mathrm{~mol} \mathrm{dm}^{-3},\left[\mathrm{H}_{2} \mathrm{SO}_{4}\right]=0.5 \times$ $10^{-4} \mathrm{~mol} \mathrm{dm}^{-3},\left[\mathrm{Hg}(\mathrm{OAc})_{2}\right]=5.0 \times 10^{-4} \mathrm{~mol} \mathrm{dm}^{-3},(\mathbf{)})$ absence of surfactants, $(\mathbf{\square})[\mathrm{CTAB}]=1.2 \times 10^{-3} \mathrm{~mol} \mathrm{dm}^{-3},(\mathbf{\Delta})[\mathrm{SDS}]=1.0 \times$ $10^{-2} \mathrm{~mol} \mathrm{dm}^{-3}$, () TX-100 $=1.0 \times 10^{-3} \mathrm{~mol} \mathrm{dm}^{-3}$, Temp. $40^{\circ} \mathrm{C}$.

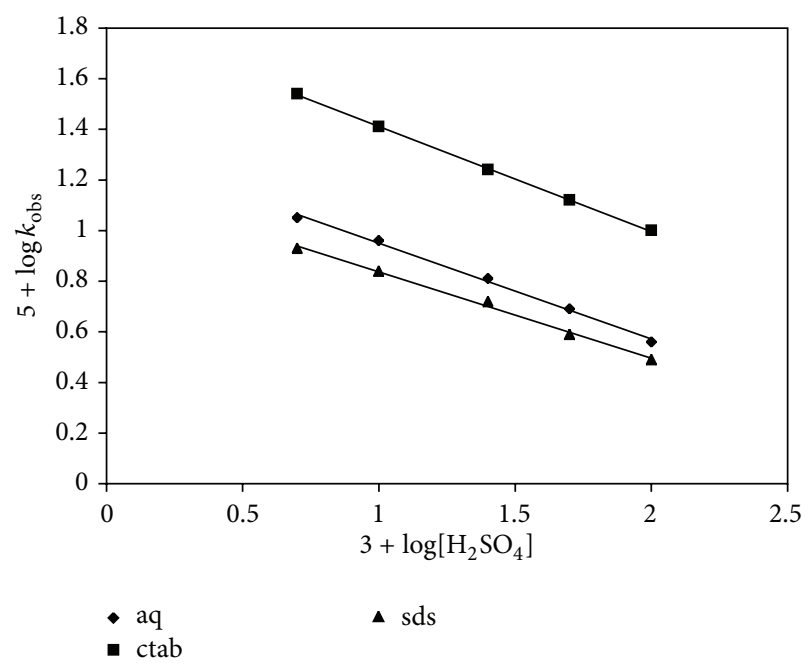

Figure 4: Effect of $\left[\mathrm{H}_{2} \mathrm{SO}_{4}\right]$; [fructose] $=2.5 \times 10^{-2} \mathrm{~mol} \mathrm{dm}^{-3}$, $[\mathrm{NBS}]=2.0 \times 10^{-4} \mathrm{~mol} \mathrm{dm}^{-3},\left[\mathrm{Hg}(\mathrm{OAc})_{2}\right]=5.0 \times 10^{-4} \mathrm{~mol} \mathrm{dm}^{-3}$, (४) absence of surfactants, (घ) $[\mathrm{CTAB}]=1.2 \times 10^{-3} \mathrm{~mol} \mathrm{dm}^{-3},(\mathbf{\Delta})$ $[\mathrm{SDS}]=1.0 \times 10^{-2} \mathrm{~mol} \mathrm{dm}^{-3}, 30 \%(\mathrm{v} / \mathrm{v})$ acetic acid, $(\mathbf{)}) \mathrm{TX}-100=$ $1.0 \times 10^{-3} \mathrm{~mol} \mathrm{dm}^{-3}$, Temp. $40^{\circ} \mathrm{C}$.

the concentration of reactants at the reaction site decreases because these are responsible for rate inhibition of micellarmediated reactions due to the exclusion of the reagent(s) from the micellar pseudophase.

3.8. Assessment for Acrylonitrile Polymerization. Addition of acrylonitrile to the reaction mixture does not induce polymerization. Therefore, the reaction does not involve the formation of free radicals. The observations demonstrate that no free radicals are formed in the reaction mechanism. 
TABLE 3: Effect of temperature on $k_{\mathrm{obs}}$.

\begin{tabular}{|c|c|c|c|}
\hline \multirow{2}{*}{${ }^{\circ} \mathrm{C}$, temperature } & \multicolumn{3}{|c|}{$10^{4}, k_{\mathrm{obs}} \mathrm{s}^{-1}$} \\
\hline & $\left(\right.$ Aqueous $^{\mathrm{a}}$ ) & $\left(\mathrm{CTAB}^{\mathrm{b}}\right)$ & $\left(\mathrm{SDS}^{\mathrm{c}}\right)$ \\
\hline 30 & 0.57 & 1.82 & 0.49 \\
\hline 35 & 0.79 & 2.89 & 0.67 \\
\hline 40 & 1.11 & 3.50 & 0.86 \\
\hline 45 & 1.48 & 4.08 & 1.21 \\
\hline 50 & 1.88 & 5.63 & 1.70 \\
\hline \multicolumn{4}{|l|}{ Activation parameters } \\
\hline$E_{a}\left(\mathrm{~kJ} \mathrm{~mol}^{-1}\right)$ & 47.69 & 40.69 & 48.27 \\
\hline $\log p_{z}\left(\mathrm{dm}^{3} \mathrm{~mol}^{-1} \mathrm{sec}^{-1}\right)$ & 4.0 & 3.33 & 3.99 \\
\hline$\Delta H\left(\mathrm{~kJ} \mathrm{~mol}^{-1}\right)$ & 45.09 & 38.09 & 45.67 \\
\hline$-\Delta S\left(\mathrm{JK}^{-1} \mathrm{~mol}^{-1}\right)$ & 320.96 & 311.43 & 323.08 \\
\hline$\Delta G\left(\mathrm{~kJ} \mathrm{~mol}^{-1}\right)$ & 145.55 & 135.56 & 146.97 \\
\hline
\end{tabular}

${ }^{\mathrm{a}}$ Reaction conditions: $\left[\right.$ fructose] $=2.5 \times 10^{-2} \mathrm{~mol} \mathrm{dm}^{-3},[\mathrm{NBS}]=2.0 \times$ $10^{-4} \mathrm{~mol} \mathrm{dm}^{-3},\left[\mathrm{H}_{2} \mathrm{SO}_{4}\right]=0.5 \times 10^{-4} \mathrm{~mol} \mathrm{dm}^{-3},\left[\mathrm{Hg}(\mathrm{OAc})_{2}\right]=5.0 \times$ $10^{-4} \mathrm{~mol} \mathrm{dm}^{-3}$, and $30 \%$ acetic acid (v/v).

${ }^{\mathrm{b}}$ Reaction conditions: [fructose] $=2.5 \times 10^{-2} \mathrm{~mol} \mathrm{dm}^{-3},[\mathrm{NBS}]=2.0 \times$ $10^{-4} \mathrm{~mol} \mathrm{dm}^{-3},\left[\mathrm{H}_{2} \mathrm{SO}_{4}\right]=0.5 \times 10^{-4} \mathrm{~mol} \mathrm{dm}^{-3},\left[\mathrm{Hg}(\mathrm{OAc})_{2}\right]=5.0 \times$ $10^{-4} \mathrm{~mol} \mathrm{dm}^{-3},[\mathrm{CTAB}]=1.2 \times 10^{-3} \mathrm{~mol} \mathrm{dm}^{-3}$, and $30 \%$ acetic acid $(\mathrm{v} / \mathrm{v})$.

${ }^{\mathrm{c}}$ Reaction conditions: [fructose] $=2.5 \times 10^{-2} \mathrm{~mol} \mathrm{dm}^{-3}$, [NBS] $=2.0 \times$ $10^{-4} \mathrm{~mol} \mathrm{dm}^{-3},\left[\mathrm{H}_{2} \mathrm{SO}_{4}\right]=0.5 \times 10^{-4} \mathrm{~mol} \mathrm{dm}^{-3},\left[\mathrm{Hg}(\mathrm{OAc})_{2}\right]=5.0 \times$ $10^{-4} \mathrm{~mol} \mathrm{dm}^{-3}$, [SDS] $=1.0 \times 10^{-2} \mathrm{~mol} \mathrm{dm}^{-3}$, and $30 \%$ acetic acid $(\mathrm{v} / \mathrm{v})$.

3.9. Temperature Effect and Activation Parameters. The oxidation of fructose was studied at $30-50^{\circ} \mathrm{C}$ and the data are presented in Table 3 . Arrhenius parameters evaluated from linear plots of $\log k_{\text {obs }}$ versus $1 / T$ were computed from Arrhenius and Eyring equations (Figure 5) in Table 3. The catalytic behavior of CTAB and TX-100 micelles indicates that the complex of fructose-NBS has the negative charge. The cationic head group may form an ion pair with the reactive and existing complex of fructose-NBS. As a result, a large number of fructose-NBS complexes are incorporated into the small volume of cationic micelles. But the nonionic micelles form hydrogen bond with the fructose-NBS complex. In the presence of SDS, on the other hand, there is electrostatic repulsion between the negative head group of SDS micelles and the reactive species of fructose-NBS complex. The result is that slightly inhibitory effect is possible. A higher value of $E_{a}$ in the presence of SDS shows the slightly inhibitory effect on the rate of reaction whereas a low value in the presence of CTAB and TX-100 shows the catalytic effect. The large negative value of $\Delta S^{\#}$ in the presence of CTAB and TX-100 indicates that more ordered activated complex is formed. The fairly high positive values of $\Delta H^{\#}$ and $\Delta G^{\#}$ indicate that the transition state is highly solvated. The nearly same value of $\Delta G^{\#}$ in the absence and presence of surfactant indicated operation of similar reaction mechanism in both cases. Here, $E_{a}$ is energy of activation, $\Delta H^{\#}$ is enthalpy of activation, $\Delta S_{\#}$ is entropy of activation, and $\Delta G^{\#}$ is free entropy of activation.

3.10. Mechanism. The monosaccharides are considered as a unit of disaccharides and on hydrolysis disaccharides give monosaccharide units. D-sucrose hydrolyzes into two monosaccharides-glucose and fructose. The monosaccharides are considered as a polyol and the reactivities of $-\mathrm{OH}$

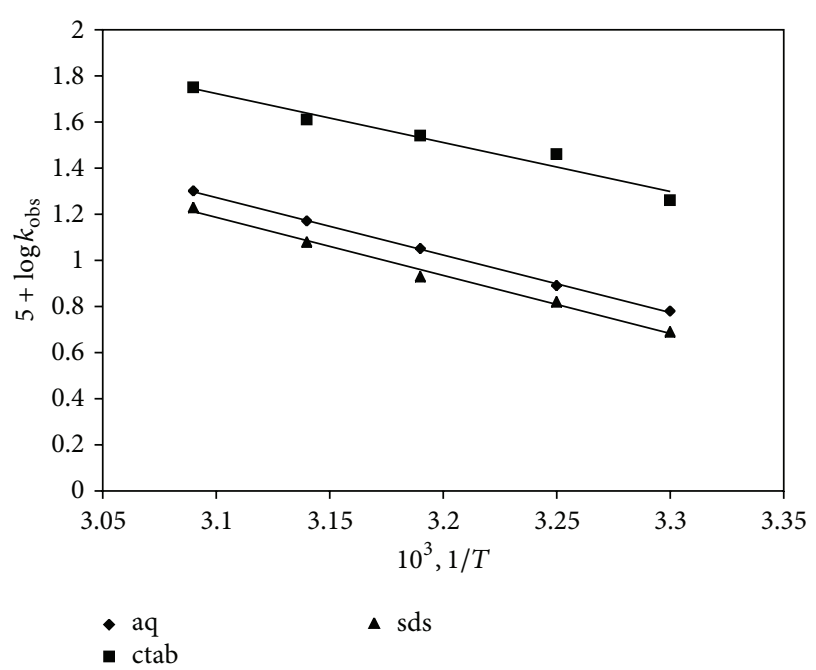

FIGURE 5: Effect of temperature; [fructose] $=2.5 \times 10^{-2} \mathrm{~mol} \mathrm{dm}^{-3}$, $[\mathrm{NBS}]=2.0 \times 10^{-4} \mathrm{~mol} \mathrm{dm}^{-3},\left[\mathrm{H}_{2} \mathrm{SO}_{4}\right]=0.5 \times 10^{-4} \mathrm{~mol} \mathrm{dm}^{-3}$, $\left[\mathrm{Hg}(\mathrm{OAc})_{2}\right]=5.0 \times 10^{-4} \mathrm{~mol} \mathrm{dm}^{-3},(\boldsymbol{)})$ absence of surfactants, $(\mathbf{\square})$ $[\mathrm{CTAB}]=1.2 \times 10^{-3} \mathrm{~mol} \mathrm{dm}^{-3},(\mathbf{\Delta})[\mathrm{SDS}]=1.0 \times 10^{-2} \mathrm{~mol} \mathrm{dm}^{-3},(\mathbf{)})$ TX-100 $=1.0 \times 10^{-3} \mathrm{~mol} \mathrm{dm}^{-3}, 30 \%(\mathrm{v} / \mathrm{v})$ acetic acid.

groups can be influenced by the presence of the carbonyl group. Monosaccharides exist mainly as pyranoid and furanoid forms, with the former being more stable [32].

On the other hand, NBS exists in the following equilibria.

Reactive Species of NBS in Aqueous Medium. Consider

$$
\begin{gathered}
\mathrm{NBS}+\mathrm{H}_{2} \mathrm{O} \rightleftharpoons \mathrm{NHS}+\mathrm{HOBr} \\
\mathrm{HOBr}+\mathrm{H}^{+} \rightleftharpoons\left(\mathrm{H}_{2} \mathrm{OBr}\right)^{+} \\
\mathrm{NBS}+\mathrm{H}^{+} \rightleftharpoons(\mathrm{NBSH})^{+} \\
\mathrm{NBS}+\mathrm{H}^{+} \rightleftharpoons \mathrm{NHS}+\mathrm{Br}^{+}
\end{gathered}
$$

Since, on assumption of NBS or (NBSH) ${ }^{+}$as the reactive species, the rate law fails to explain the negative effect of phthalimide, hence, neither of these species, NBS and $(\mathrm{NBSH})^{+}$, can be taken as the reactive species. When HOBr is taken as the reactive species, the rate law explains the negative effect of $\left[\mathrm{H}^{+}\right]$and [NHS]. Thus, $\mathrm{HOBr}$ is taken as the most reactive species, which gave the rate law capable of explaining all the kinetic observations and other effects.

According to above experimental conditions $\mathrm{HOBr}$ is the most reactive species of NBS and considering the fact that one mole of D-sucrose is oxidized by two moles of NBS in Scheme 2.

In Scheme 2, $S$ stands for D-sucrose, $K_{1}, K_{2}$ are the equilibrium constants for steps 1 and $2, k$ is the rate constant, and $\mathrm{A}^{-}$is intermediate species. Equation (8) is in good agreement with the experimental results. The rate of disappearance of [NBS] can be expressed in (10). Equations (11) and (12) 


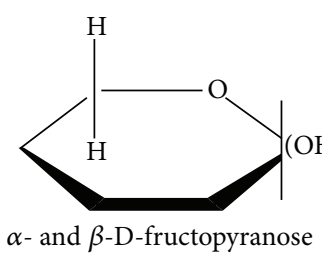

(58\%)

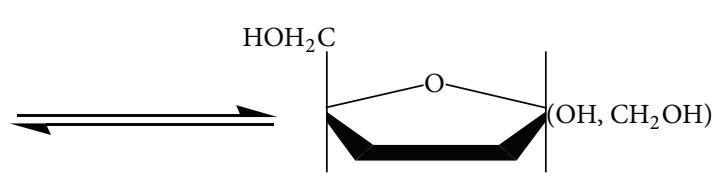

$\alpha$ - and $\beta$-D-fructofuranose (42\%)

SCHEME 1: Species of D-sucrose.

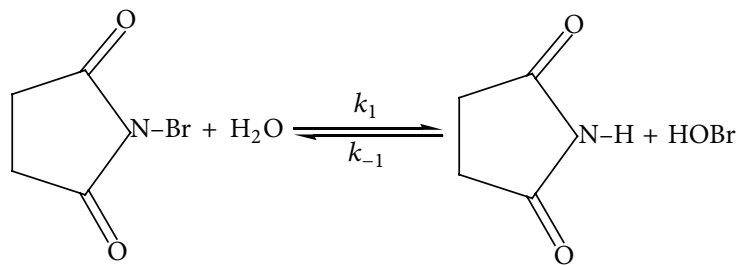

$\mathrm{N}$-bromosuccinimide

Succinimide

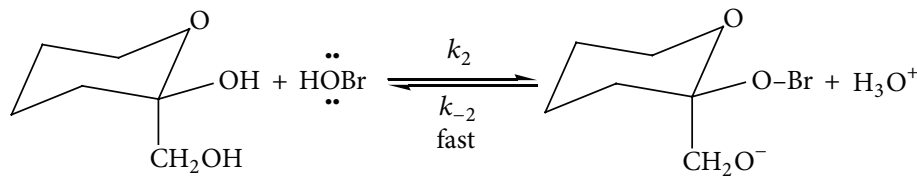

Fructose

$\mathrm{A}^{-}$
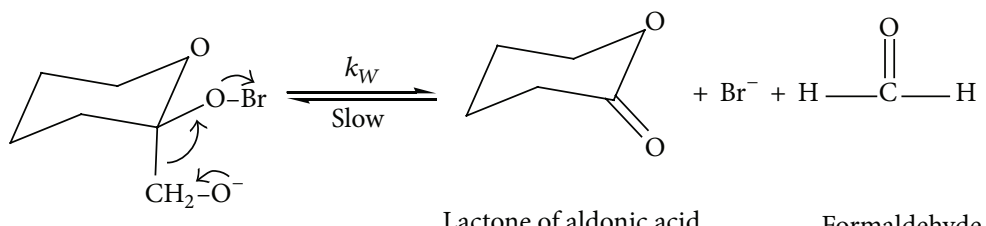

SCHEME 2: Mechanism of oxidation of fructose by NBS.

satisfactorily explain the kinetic results with respect to [NBS], [D-sucrose], $\left[\mathrm{H}_{2} \mathrm{SO}_{4}\right]$, and [NHS]. Consider

$$
-\frac{d[\mathrm{NBS}]}{d t}=\frac{k k_{1} k_{2}[\text { Fructose }][\mathrm{NBS}]_{T}}{[\mathrm{NHS}]\left[\mathrm{H}^{+}\right]+k_{1} k_{2}[\text { Fructose }]+k_{1}\left[\mathrm{H}^{+}\right]},
$$

where

$$
\begin{gathered}
{[\mathrm{NBS}]_{T}=[\mathrm{NBS}]+[\mathrm{HOBr}]+\left[\mathrm{A}^{-}\right],} \\
\text {rate }=k_{\mathrm{obs}}[\mathrm{NBS}]_{T}, \\
k_{\mathrm{obs}}=\frac{\text { rate }}{[\mathrm{NBS}]_{T}} \\
=\frac{k k_{1} k_{2}[\text { Fructose }]}{[\mathrm{NHS}]\left[\mathrm{H}^{+}\right]+k_{1} k_{2}[\text { Fructose }]+k_{1}\left[\mathrm{H}^{+}\right]}, \\
\frac{1}{k_{\mathrm{obs}}}=\frac{\left[\mathrm{H}^{+}\right][\mathrm{NHS}]}{k k_{1} k_{2}[\text { Fructose }]}+\frac{\left[\mathrm{H}^{+}\right]}{k k_{2}[\text { Fructose }]}+\frac{1}{k} .
\end{gathered}
$$

3.11. Effect of Varying [Surfactants]. In the case of D-sucrose, the cationic surfactant CTAB and nonionic surfactant TX100 have been found to show the rate accelerating effect whereas the anionic surfactant SDS has been found to show the rate retarding effect. In all cases, after a certain concentration of surfactant, the rate constant attains a limiting value. In presence of the cationic surfactant CTAB, both the reactants, that is, D-sucrose (it should hydrolyse into glucose and fructose with negative charge) and NBS, are preferably partitioned in the stern layer of CTAB (a cationic surfactant), bearing the positively charged micellar head groups, and consequently the rate is accelerated (Figures 6 and 7), (Table 4). In presence of the nonionic surfactant TX100 , both the reactants, that is, D-sucrose (a hydrophilic substance) and NBS, are preferably partitioned in the stern layer of TX-100 (a nonionic surfactant), bearing not any charge on micellar head groups, and consequently the rate is accelerated. The anionic species of D-sucrose (Scheme 1) and NBS is being repelled by the negatively charged micellar head groups of SDS (an anionic surfactant) and consequently the rate is retarded (Figures 8 and 9), (Table 4). A possible 
TABLE 4: Effect of surfactants on $k_{\text {obs }}$.

\begin{tabular}{lccc}
\hline $10^{3},[\mathrm{CTAB}] \mathrm{mol} \mathrm{dm}^{-3}$ & $10^{4}, k_{\mathrm{obs}} \mathrm{s}^{-1}$ & $\begin{array}{c}10^{2},[\mathrm{SDS}] \\
\mathrm{mol} \mathrm{dm}^{-3}\end{array}$ & $10^{4}, k_{\mathrm{obs}} \mathrm{s}^{-1}$ \\
\hline 0 & 1.11 & 0 & 1.11 \\
0.2 & 1.25 & 0.2 & 1.02 \\
0.4 & 1.31 & 0.4 & 1.0 \\
0.6 & 1.50 & 0.6 & 0.97 \\
0.8 & 2.16 & 0.75 & 0.93 \\
1.0 & 2.90 & 0.8 & 0.91 \\
1.2 & 3.50 & 1.0 & 0.86 \\
1.4 & 2.40 & 1.1 & 0.84 \\
1.6 & 2.0 & 1.2 & 0.81 \\
1.8 & 1.72 & 1.4 & 0.78 \\
& & 1.6 & -
\end{tabular}

Other parameters

$k_{w}, \mathrm{~s}^{-1}\left(10^{-4}\right)$

1.07

1.31

$\left(K_{S}+K_{\mathrm{O}}\right), \mathrm{dm}^{3} \mathrm{~mol}^{-1}$

2.57

\section{$\left(10^{-6}\right)$}

Reaction conditions: [fructose] $=2.5 \times 10^{-2} \mathrm{~mol} \mathrm{dm}^{-3},[\mathrm{NBS}]=2.0 \times$ $10^{-4} \mathrm{~mol} \mathrm{dm}^{-3},\left[\mathrm{H}_{2} \mathrm{SO}_{4}\right]=0.5 \times 10^{-4} \mathrm{~mol} \mathrm{dm}^{-3},\left[\mathrm{Hg}(\mathrm{OAc})_{2}\right]=5.0 \times$ $10^{-4} \mathrm{~mol} \mathrm{dm}^{-3}, 30 \%$ acetic acid (v/v), and temperature $40^{\circ} \mathrm{C}$.

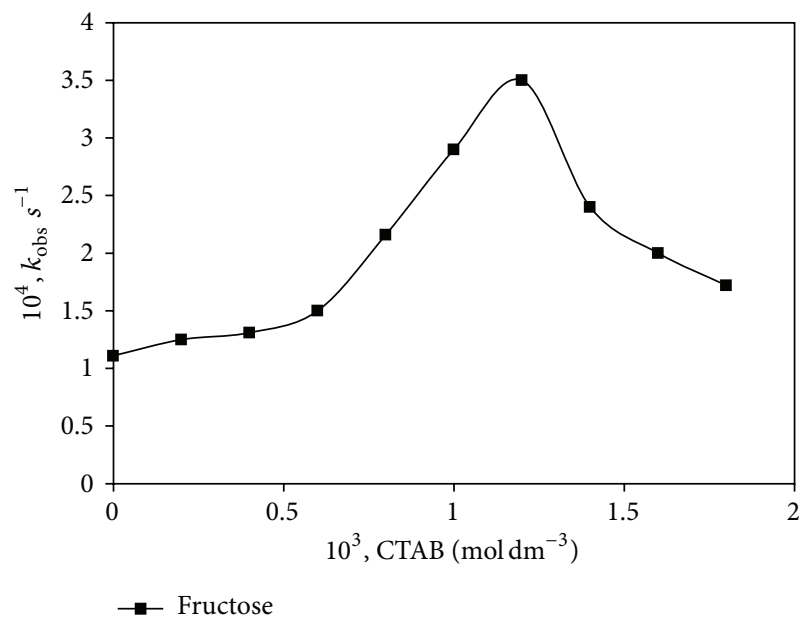

Figure 6: Effect of [CTAB] on fructose; [fructose] $=2.5 \times$ $10^{-2} \mathrm{~mol} \mathrm{dm}^{-3},\left[\mathrm{H}_{2} \mathrm{SO}_{4}\right]=0.5 \times 10^{-4} \mathrm{~mol} \mathrm{dm}^{-3},\left[\mathrm{Hg}(\mathrm{OAc})_{2}\right]=5.0 \times$ $10^{-4} \mathrm{~mol} \mathrm{dm}^{-3},[\mathrm{NBS}]=2.0 \times 10^{-4} \mathrm{~mol} \mathrm{dm}^{-3}, 30 \%(\mathrm{v} / \mathrm{v})$ acetic acid, Temp. $40^{\circ} \mathrm{C}$.

arrangement (although highly schematic) could be as shown in Scheme 3, which indicates the probable reaction site to be the "Stern and Gouy-Chapman layers" junctural region.

3.12. The Kinetic Model to Explain the Micellar Effects. Micellar catalysis critically depends on the interactions of the micelle with the substrate(s) and the activated complex. This is an extremely complicated problem because a number of different interactions are involved including those associated with the head group of the surfactant, the different segments of the alkyl chain, and the counterions. In Berezin's model,

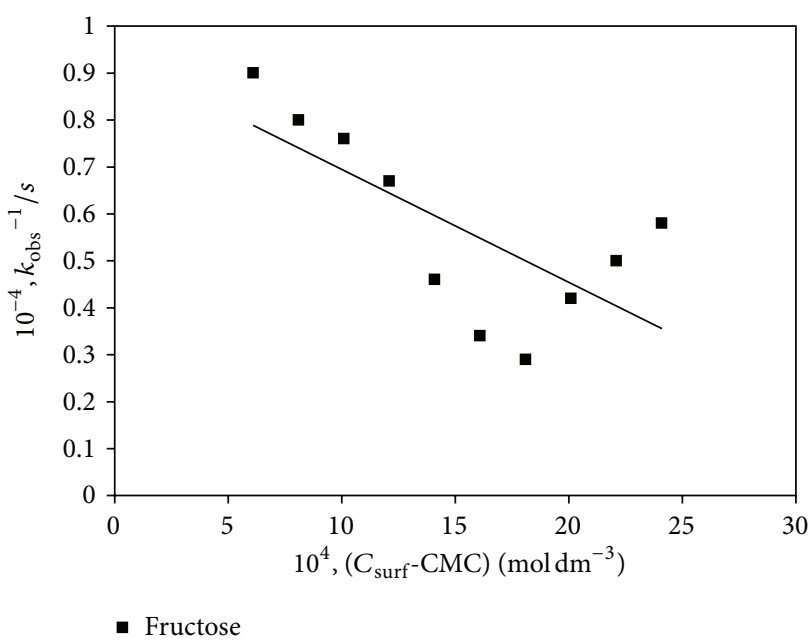

Figure 7: Plot between $\left(C_{\text {surf }}\right.$-CMC) versus $k_{\text {obs }}^{-1}$ (For CTAB); [fructose] $=2.5 \times 10^{-2} \mathrm{~mol} \mathrm{dm}^{-3},[\mathrm{NBS}]=2.0 \times 10^{-4} \mathrm{~mol} \mathrm{dm}^{-3}$, $\left[\mathrm{H}_{2} \mathrm{SO}_{4}\right]=0.5 \times 10^{-4} \mathrm{~mol} \mathrm{dm}^{-3},\left[\mathrm{Hg}(\mathrm{OAc})_{2}\right]=5.0 \times 10^{-4} \mathrm{~mol} \mathrm{dm}^{-3}$, $30 \%(\mathrm{v} / \mathrm{v})$ acetic acid, Temp. $40^{\circ} \mathrm{C}$.

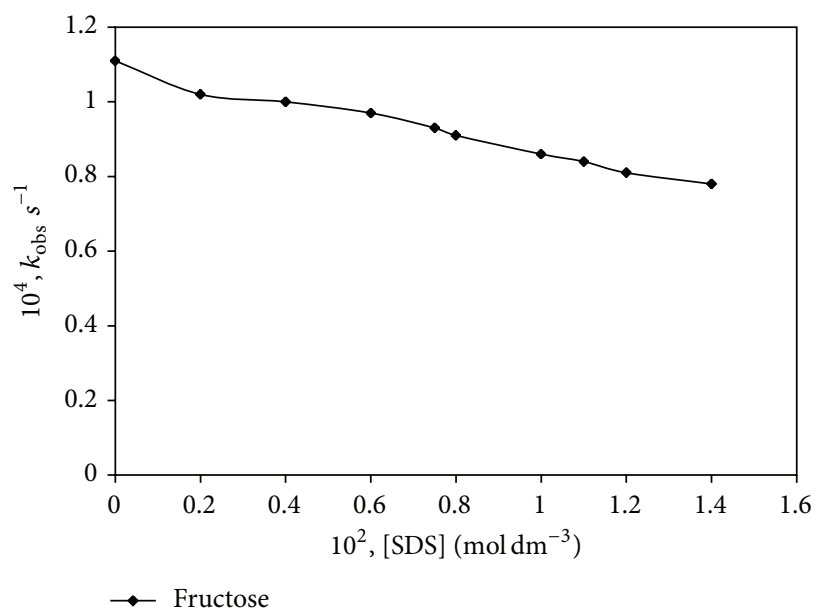

FIGURE 8: Effect of [SDS] on fructose; [fructose] $=2.5 \times$ $10^{-2} \mathrm{~mol} \mathrm{dm}^{-3},\left[\mathrm{H}_{2} \mathrm{SO}_{4}\right]=0.5 \times 10^{-4} \mathrm{~mol} \mathrm{dm}^{-3},\left[\mathrm{Hg}(\mathrm{OAc})_{2}\right]=5.0 \times$ $10^{-4} \mathrm{~mol} \mathrm{dm}^{-3},[\mathrm{NBS}]=2.0 \times 10^{-4} \mathrm{~mol} \mathrm{dm}^{-3}, 30 \%(\mathrm{v} / \mathrm{v})$ acetic acid, Temp. $40^{\circ} \mathrm{C}$.

a solution above the CMC may be considered as a twophase system, consisting of an aqueous phase and a micellar pseudophase. The reactants ( $\mathrm{S}$ and $\mathrm{O}$ ) may be distributed as shown in Scheme 4. A quantitative rate expression for a bimolecular reaction occurring only in aqueous $\left(k_{W}\right.$ path) and micellar ( $k_{M}$ path) phase for the pseudo-first-order rate constant is given in Scheme 4. Consider

$$
k_{\mathrm{obs}}=\frac{k_{W}+k_{M}^{\prime} K_{\mathrm{S}} K_{\mathrm{O}}\left(C_{\text {surf }}-\mathrm{CMC}\right)}{\left[1+K_{\mathrm{S}}\left(C_{\text {surf }}-\mathrm{CMC}\right)\right]\left[1+K_{\mathrm{O}}\left(C_{\text {surf }}-\mathrm{CMC}\right)\right]},
$$

where $K_{\mathrm{S}}$ and $K_{\mathrm{O}}$ are the association constants of D-sucrose and NBS, respectively, with surfactants, $C_{\text {surf }}$ is the analytical concentration of surfactants, $k_{M}^{\prime}=\left(k_{M} / V\right), V$ is the molar 


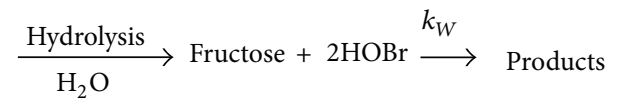

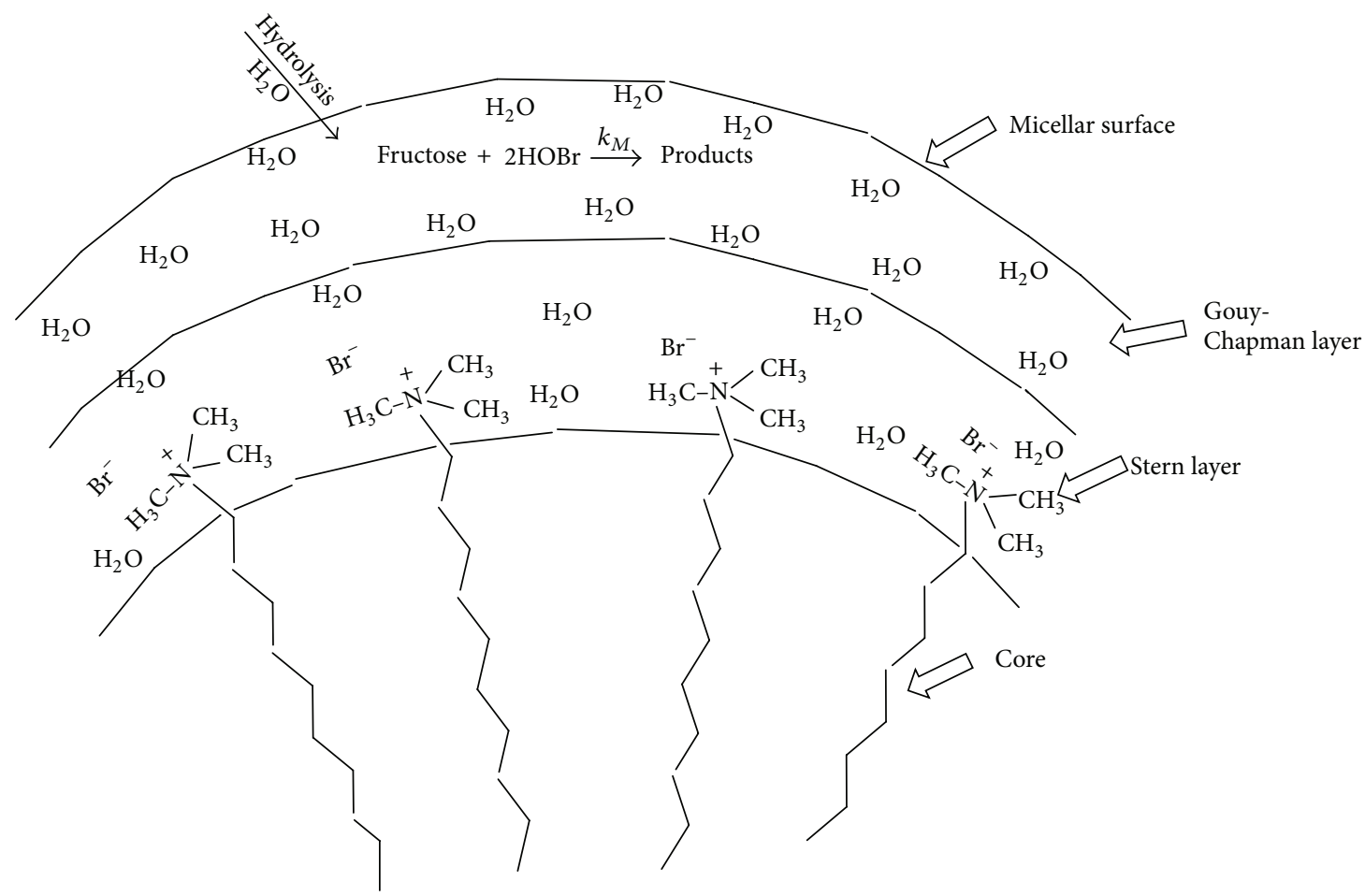

SCHEME 3: Schematic model showing probable location of reactants.

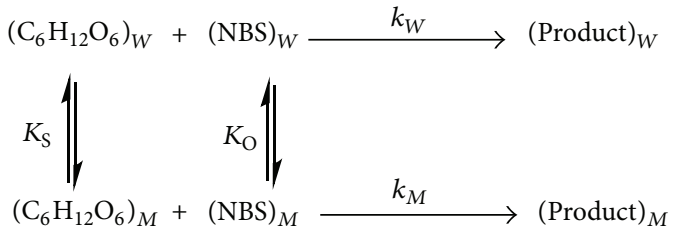

Scheme 4: Berezin's model.

volume of the micelle, and $k_{W}$ and $k_{M}$ are the pseudo-firstorder rate constants in absence and presence of micelles, respectively. Since the oxidant will be uncharged species and the substrate is large molecules, the hydrophobic and electrostatic interactions will be large and hence it may be expected that $K_{\mathrm{S}}$ and $K_{\mathrm{O}}$ will be high. Since $C_{\text {surf }}$ is small it may be possible that $k_{W} \gg k_{M}^{\prime} K_{\mathrm{S}} K_{\mathrm{O}}\left(C_{\text {surf }}-\mathrm{CMC}\right)$ so that (13) takes the form

$$
\begin{aligned}
& k_{\text {obs }} \\
& =\frac{k_{W}}{1+\left(K_{\mathrm{S}}+K_{\mathrm{O}}\right)\left(C_{\text {surf }}-\mathrm{CMC}\right)+K_{\mathrm{S}} K_{\mathrm{O}}\left(C_{\text {surf }}-\mathrm{CMC}\right)^{2}} .
\end{aligned}
$$

Again, since $\left(C_{\text {surf }}-\mathrm{CMC}\right)$ is very small, the terms containing $\left(C_{\text {surf }}-\mathrm{CMC}\right)^{2}$ may be neglected, and (14) may be rearranged to

$$
\frac{1}{k_{\mathrm{obs}}}=\frac{1}{k_{W}}+\frac{K_{\mathrm{S}}+K_{\mathrm{O}}}{k_{W}}\left(C_{\text {surf }}-\mathrm{CMC}\right) .
$$

Plot of $k_{\mathrm{obs}}^{-1}$ versus $\left(C_{\text {surf }}-\mathrm{CMC}\right)$ for D-sucrose is linear (Figures 7 and 9).

\section{Summary}

In summary, the following conclusions can be drawn. Kinetic parameters for the reaction were determined, assuming that the dominant active species of NBS is $\mathrm{HOBr}$. Activation and thermodynamic parameters have been evaluated for both in absence and presence of the surfactants. The CMC values are lower than those given in the literature for aqueous solutions of surfactants without added electrolyte. The reaction was found to be first and fractional order each with respect to the oxidant and the reductant. The mechanism of the reaction involves (i) hydrolysis of D-sucrose into monosaccharide units, glucose and fructose, and (ii) oxidation of both monosaccharide units. Oxidation product is lactone of aldonic acid. The rate of oxidation increases with increasing concentration of CTAB and TX-100. The SDS shows inhibitory effect. The effect of micellization can be correlated with the nature of the reducing substrates and 


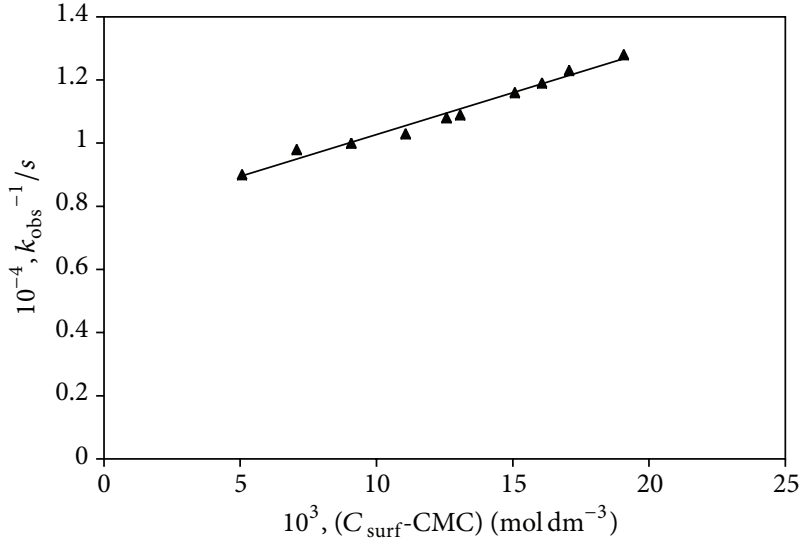

- Fructose

Figure 9: Plot between $\left(C_{\text {surf }}\right.$-CMC) versus $k_{\text {obs }}^{-1}$ (For SDS); [fructose $]=2.5 \times 10^{-2} \mathrm{~mol} \mathrm{dm}{ }^{-3},[\mathrm{NBS}]=2.0 \times 10^{-4} \mathrm{~mol} \mathrm{dm}^{-3},\left[\mathrm{H}_{2} \mathrm{SO}_{4}\right]$ $=0.5 \times 10^{-4} \mathrm{~mol} \mathrm{dm}^{-3},\left[\mathrm{Hg}(\mathrm{OAc})_{2}\right]=5.0 \times 10^{-4} \mathrm{~mol} \mathrm{dm}^{-3}, 30 \%(\mathrm{v} / \mathrm{v})$ acetic acid, Temp. $40^{\circ} \mathrm{C}$.

the reaction conditions. This is in agreement with the qualitative knowledge about the nature of D-sucrose and NBS in $\mathrm{H}_{2} \mathrm{SO}_{4}$ medium.

\section{Conflict of Interests}

The author declares that there is no conflict of interests regarding the publication of this paper.

\section{Acknowledgments}

The author gratefully wishes to thank the Chhattisgarh Council of Science and Technology (CGCOST) for the Research Project Grant. The author also thanks Professor Laurence S. Romsted, Department of Chemistry, Wright-Rieman Laboratories, New Jersey, USA, for valuable discussions and fruitful suggestions.

\section{References}

[1] J. W. Park, M.-A. Chung, and K. M. Choi, "Properties of sodium dodecyl sulfate/Triton X-100 mixed micelle," Bulletin of the Korean Chemical Society, vol. 10, no. 5, pp. 437-442, 1989.

[2] B. Samiey, K. Alizadeh, M. A. Moghaddasi, M. F. Mousavi, and N. Alizadeh, "Study of kinetics of Bromophenol blue fading in the presence of SDS, DTAB and Triton X-100 by classical model," Bulletin of the Korean Chemical Society, vol. 25, no. 5, pp. 726-736, 2004.

[3] H. Gharibi, B. Sohrabi, S. Javadian, and M. Hashemianzadeh, "Study of the electrostatic and steric contributions to the free energy of ionic/nonionic mixed micellization," Colloids and Surfaces A: Physicochemical and Engineering Aspects, vol. 244, no. 1-3, pp. 187-196, 2004.

[4] Z. Zhi-Guo and Y. Hong, "Interaction of nonionic surfactant $\mathrm{AEO}_{9}$ with ionic surfactants," Journal of Zhejiang University: Science B, vol. 6, no. 6, pp. 597-601, 2005.
[5] G. Briganti, S. Puvvada, and D. Blankschtein, "Effect of urea on micellar properties of aqueous solutions of nonionic surfactants," Journal of Physical Chemistry, vol. 95, no. 22, pp. 89898995, 1991.

[6] H. H. Paradies, The Journal of Physical Chemistry A, vol. 84, p. 599, 1980.

[7] A. B. Mandal, B. U. Nair, and D. Ramaswamy, "Determination of the critical micelle concentration of surfactants and the partition coefficient of an electrochemical probe by using cyclic voltammetry," Langmuir, vol. 4, no. 3, pp. 736-739, 1988.

[8] T. van den Boomgaard and J. Lyklema, "On the influence of concentrated electrolytes on the association behaviour of a nonionic surfactant," Progress in Colloid and Polymer Science, vol. 68, pp. 25-32, 1983.

[9] J. P. Hanrahan, K. J. Ziegler, J. P. Galvin, and J. D. Holmes, "Water-in- $\mathrm{CO}_{2}$ emulsions: reaction vessels for the production of tetra-ethyl pyrone," Langmuir, vol. 20, no. 11, pp. 4386-4390, 2004.

[10] S. K. Mehta, A. K. Malik, U. Gupta, and A. L. J. Rao, Electronic Journal of Environmental, Agricultural and Food Chemistry, vol. 3, no. 6, p. 784, 2004.

[11] N. J. Turro, P.-L. Kuo, P. Somasundaran, and K. Wong, "Surface and bulk interactions of ionic and nonionic surfactants," The Journal of Physical Chemistry, vol. 90, no. 2, pp. 288-291, 1986.

[12] A. B. Mandal, D. V. Ramesh, and S. C. Dhar, "Physicochemical studies of micelle formation on sepia cartilage collagen solutions in acetate buffer and its interaction with ionic and nonionic micelles. Hydrodynamic and thermodynamic studies," European Journal of Biochemistry, vol. 169, no. 3, pp. 617-628, 1987.

[13] H.-K. Ko, B.-D. Park, and J.-C. Lim, "Studies on phase behavior in systems containing NP series nonionic surfactant, water, and D-limonene," Journal of Korean Industrial and Engineering Chemistry, vol. 11, no. 6, pp. 679-686, 2000.

[14] A. Rodríguez, M. Muñoz, M. del Mar Graciani, S. Fernández Chacón, and M. L. Moyá, "Kinetic study in water-ethylene glycol cationic, zwitterionic, nonionic, and anionic micellar solutions.," Langmuir, vol. 9, no. 3, pp. 9945-9952, 2004.

[15] N. J. Buurma, A. M. Herranz, and J. B. F. N. Engberts, "The nature of the micellar Stern region as studied by reaction kinetics," Journal of the Chemical Society-Perkin Transactions, vol. 2, no. 1, pp. 113-119, 1999.

[16] M. Múñoz, A. Rodríguez, and M. del Mar Graciani, "Study of the reaction 1,1,1-trichloro-2,2-bis(p-chlorophenyl)ethane + $\mathrm{OH}^{-}$in nonionic micellar solutions," Langmuir, vol. 15, pp. 7876-7879, 1999.

[17] J. Perkowski, J. Mayer, and L. Kos, "Reactions of non-ionic surfactants, triton X-n type, with $\mathrm{OH}$ radicals. A review," Fibrese Textiles in Eastern Europe, vol. 13, no. 2, pp. 81-85, 2005.

[18] F. Mahmood, M. Arif, A. Ahmed, and S. B. Niazi, "Interaction studies of tween-40 with some acidic species at 20 C," Journal of Research (Science), vol. 11, no. 1, p. 1, 2000.

[19] Kabir-ud-Din, A. M. A. Morshed, and Z. Khan, "Influence of sodium dodecyl sulfate/TritonX-100 micelles on the oxidation of D-fructose by chromic acid in presence of $\mathrm{HClO}_{4}$," Carbohydrate Research, vol. 337, no. 17, pp. 1573-1583, 2002.

[20] K.-H. Chung and S. Kim, "Oxidations of cyclohexanols by Nbromosuccinimide and sodium hypochlorite," Bulletin of the Korean Chemical Society, vol. 7, no. 2, pp. 111-113, 1986.

[21] S. P. Mushran, K. Singh, L. Pandey, and S. M. Pandey, Proceedings of the Indian National Science Academy, vol. 46, no. 2, p. 119, 1980. 
[22] S. K. Mavalangi, M. R. Kembhavi, and S. T. Nandibewoor, "Oxidation of ethylenediaminetetraacetic acid by $\mathrm{N}$ bromosuccinimide in aqueous alkaline medium-a kinetic study," Turkish Journal of Chemistry, vol. 25, no. 3, pp. 355-363, 2001.

[23] N. A. M. Farook, "Kinetics and mechanism of oxidation of 4-oxoacids by N-bromosuccinimide in aqueous acetic acid medium," Journal of the Iranian Chemical Society, vol. 3, no. 4, pp. 378-386, 2006.

[24] R. Ramachandrappa, S. M. Mayanna, and N. M. Made Gowda, "Kinetics and mechanism of oxidation of aspirin by bromamine-T, N-bromosuccinimide, and N-bromophthalimide," International Journal of Chemical Kinetics, vol. 30, no. 6, pp. 407-414, 1998.

[25] S. Pandey and S. K. Upadhyay, Indian Journal of Chemical Technology, vol. 12, no. 1, p. 35, 2005.

[26] M. Z. Barakat and M. F. A. El-Wahab, "Microdetermination of bromine or chlories in N-halogenated imides," Analytical Chemistry, vol. 26, no. 12, pp. 1973-1974, 1954.

[27] K. K. Sengupta, B. A. Begum, and B. B. Pal, "Kinetic behaviour and relative reactivities of some aldoses, amino sugars, and methylated sugars towards platinum(IV) in alkaline medium," Carbohydrate Research, vol. 309, no. 4, pp. 303-310, 1998.

[28] A. Kumar and R. N. J. Mehrotra, "Kinetics of oxidation of Aldo Sugars by quinquevalent vanadium ion in acid medium," The Journal of Organic Chemistry, vol. 40, pp. 1248-1252, 1975.

[29] K. K. Sengupta, B. A. Begum, and B. B. Pal, "Kinetics and mechanism of the oxidation of some aldoses, amino sugars and methylated sugars by tris(pyridine-2-carboxylato)manganese(III) in weakly acidic medium," Carbohydrate Research, vol. 315, no. 1-2, pp. 70-75, 1999.

[30] E. S. Amis, Solvent Effects on Reaction Rates and Mechanism, Academic Press, New York, NY, USA, 1966.

[31] A. Ray and G. Nemethy, "Effects of ionic protein denaturants on micelle formation by nonionic detergents," Journal of the American Chemical Society, vol. 93, no. 25, pp. 6787-6793, 1971.

[32] A. S. Perlin, "Ring contraction during the lead tetraacetate oxidation of reducing sugars," Canadian Journal of Chemistry, vol. 42, pp. 2365-2374, 1964. 

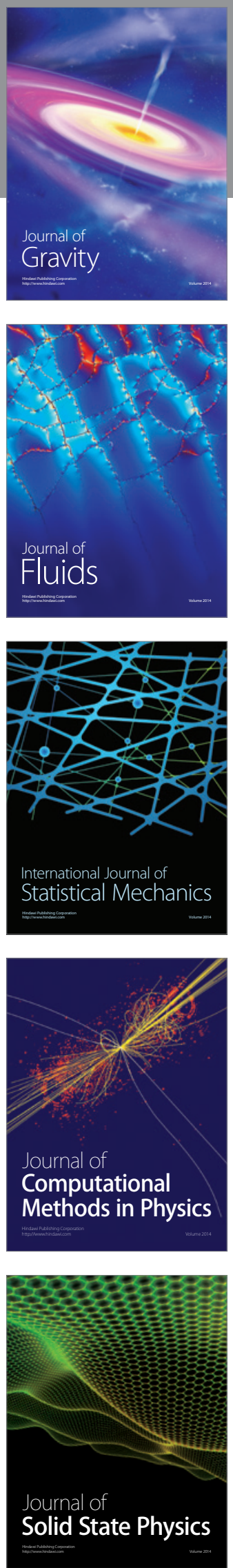

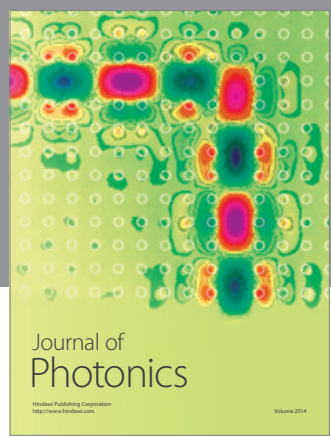

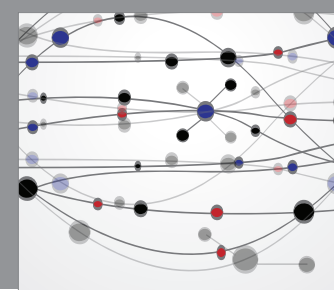

The Scientific World Journal

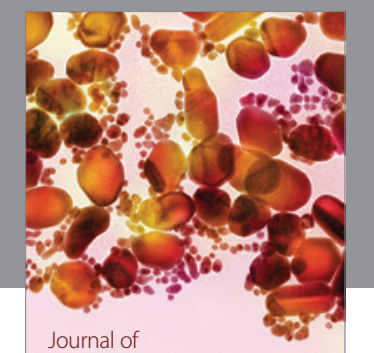

Soft Matter
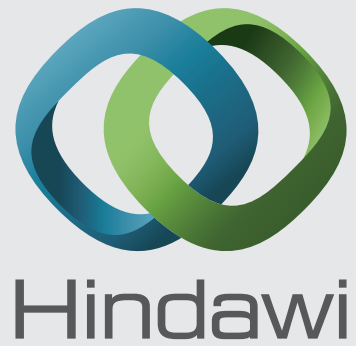

Submit your manuscripts at

http://www.hindawi.com
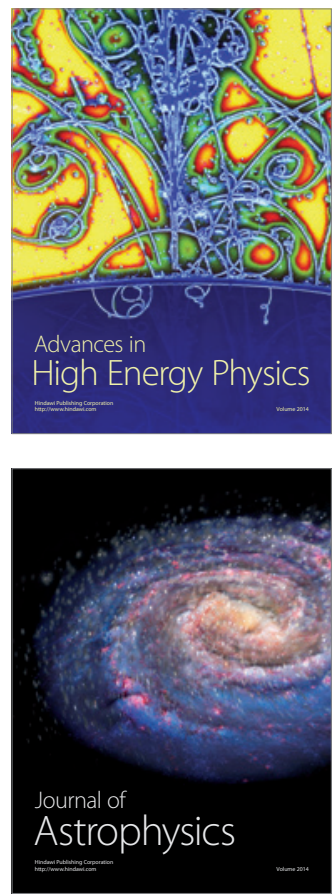
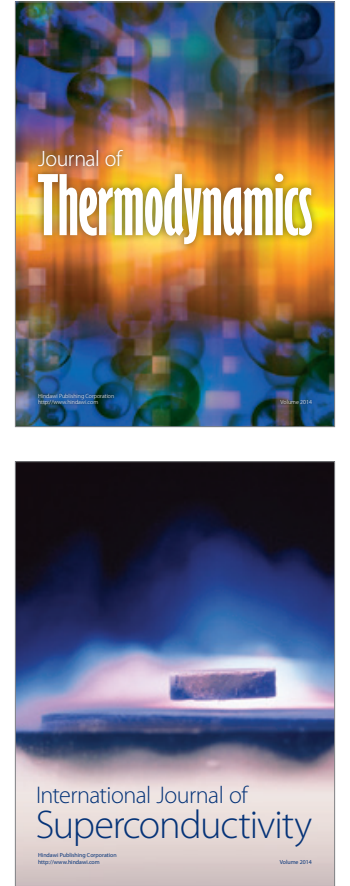
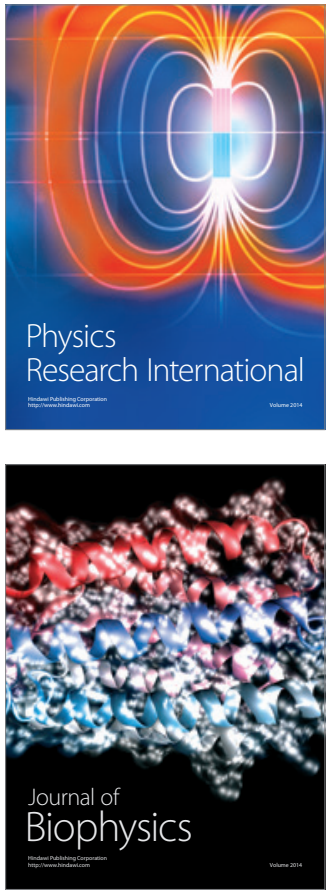
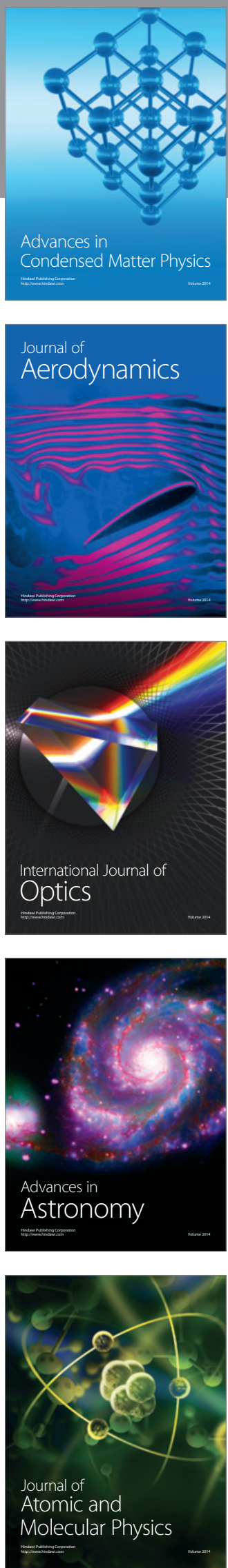